PLEASE NOTE:

This is the author's version of the manuscript accepted for publication in Journal of Alzheimer's Disease. Changes resulting from the publishing process, namely editing, corrections, final formatting for printed or online publication, and other modifications resulting from quality control procedures, may have been subsequently added.

The published version can be found in: Moreira, H. S., Lima, C. F., \& Vicente, S. (2014). Examining executive dysfunction with the Institute of Cognitive Neurology (INECO) Frontal Screening (IFS): Normative values from a healthy sample and clinical utility in alzheimers disease. Journal of Alzheimer's Disease, 42(1), 261-273. doi: 10.3233/JAD-132348 


\section{Examining executive dysfunction with the Institute of Cognitive Neurology (INECO) Frontal Screening (IFS): Normative values from a healthy sample and clinical utility in Alzheimer's disease}

Helena S. Moreira (M.Sc.) $)^{1 *}$, César F. Lima (Ph.D. $)^{1,2,3^{*}}$, and Selene G. Vicente (Ph.D.) ${ }^{1,2}$

${ }^{1}$ Faculty of Psychology and Education, University of Porto, Portugal

${ }^{2}$ Center for Psychology at University of Porto, Portugal

${ }^{3}$ Institute of Cognitive Neuroscience, University College London, United Kingdom

* These authors contributed equally to this work

Running Head: The INECO Frontal Screening (IFS) in Alzheimer's disease

Correspondence concerning this article should be addressed to Selene Vicente, Faculdade de Psicologia e de Ciências da Educação, Universidade do Porto, Rua Alfredo Allen, 4200-135 
Porto, Portugal. E-mail: svicente@fpce.up.pt. Tel: +351226079 757 / +351220 400610.

Fax: +351226079 725 .

\begin{abstract}
Background. The Institute of Cognitive Neurology (INECO) Frontal Screening (IFS) is a brief neuropsychological tool recently devised for the evaluation of executive dysfunction in neurodegenerative conditions. Objective. In this study we present a cross-cultural validation of the IFS for the Portuguese population, provide normative values from a healthy sample, determine how age and education affect performance, and inspect its clinical utility in the context of Alzheimer's disease (AD). A comparison with the Frontal Assessment Battery (FAB) was undertaken, and correlations with other well-established executive functions measures were examined. Methods. The normative sample included 204 participants varying widely in age $(20-85$ years $)$ and education $(3-21$ years $)$. The clinical sample $(n=21)$ was compared with a sample of age- and education-matched controls $(n=21)$. Healthy participants completed the IFS and the Mini-Mental State Examination (MMSE). In addition to these, the patients (and matched controls) completed the FAB and a battery of other executive tests. Results. IFS scores were positively affected by education and MMSE, and negatively affected by age. Patients underperformed controls on the IFS, and correlations were found with the Clock Drawing Test, Stroop test, and the Zoo Map and Rule Shift Card tests of The Behavioural Assessment of the Dysexecutive Syndrome. A cut-off of 17 optimally differentiated patients from controls. Whilst $88 \%$ of the IFS sub-tests discriminated patients from controls, only $67 \%$ of the FAB sub-tests did so. Conclusion. Age and education should be taken into account when interpreting performance on the IFS. The IFS is useful to detect executive dysfunction in $\mathrm{AD}$, showing good discriminant and concurrent validities.
\end{abstract}


Keywords: cognition, screening tests, executive dysfunction, INECO Frontal Screening (IFS), Alzheimer's disease, Portuguese norms

\section{Introduction}

Executive functions (EF) are "supervisory" processes that coordinate cognitive, behavioral and emotional functions to optimize performance and pursue goals [1-6]. They encompass crucial abilities such as planning, working memory, cognitive flexibility, and inhibition $[4,7,8]$. Several prefrontal regions support EF, including the dorsolateral prefrontal and the orbitofrontal cortices, and non-frontal structures are involved as well (e.g., amygdala, striatum) [3,8-10]. Healthy ageing is associated with decrements in EF [11], particularly in planning [12,13] and inhibition [13-17]. EF are compromised in neurodegenerative and cerebrovascular disorders, such as Parkinson's disease (PD) [18-20], vascular dementia (VD) [21,22], frontotemporal dementia (FTD) [21,23], and Alzheimer's disease (AD) [24-28]. Concerning $\mathrm{AD}$, breakdowns in $\mathrm{EF}$ are noticeable in the early course of the disease, possibly even before standard measures of global cognitive decline can distinguish between patients and controls [27-29]. Balota et al. [30] found that the strongest predictor of conversion from healthy aging to $\mathrm{AD}$ was performance on a Stroop task, whereas differences in declarative memory were a relatively poor predictor. Consistently, Bangert and Balota [31] showed that decline in attentional control differentiates healthy aging from the earliest stages of $\mathrm{AD}$. Assessing executive abilities may thus play a pivotal role for the early diagnosis of this disease and for the evaluation of its severity and progression [28].

Given that comprehensive batteries of EF are time consuming and can be distressing for patients (e.g., Behavioral Assessment of Dysexecutive Syndrome, BADS [32]; Neuropsychological Assessment Battery [33]), the availability of brief tools is of great clinical value. There are well-established tests for general cognitive screening, namely the 
Mini-Mental State Examination (MMSE) [34] and the Montreal Cognitive Assessment [35], but for EF they are rare. The Frontal Assessment Battery (FAB) [36] is the most frequently used one [37-41]. It has very good inter-rater reliability, internal consistency, discriminant validity, and concurrent validity $[19,36,37,41,42]$. Limitations have been identified as well, though. Some sub-tests show poor sensitivity (e.g., prehension behavior) [19], and the battery as a whole fails to discriminate AD from FTD $[43,44]$, even though specific sub-tests succeed in doing so (motor inhibitory control [44], mental flexibility, motor programming, and environmental autonomy [45]; lexical fluency [46]). It was also observed that lexical fluency, but not other sub-tests, is sensitive to executive dysfunction caused by cortical lesions restricted to the frontal cortex [47].

Torralva, Roca, Gleichgerrcht, López, and Manes [48] designed a screening test of EF, the Institute of Cognitive Neurology (INECO) Frontal Screening (IFS), aiming at providing a more sensitive measure of executive dysfunction in neurodegenerative conditions. It takes approximately 10 minutes to administer and the total score ranges between 0 and 30 , corresponding to the sum of eight sub-tests scores. The sub-tests cover three domains (response inhibition and set shifting, abstraction, and working memory), and they inspect the following specific processes: motor programming (task: Luria's motor series fist, edge, palm), sensitivity to interference (conflicting instructions), inhibitory control (Go/no Go), verbal inhibitory control (modified Hayling test), abstraction capacity (proverb interpretation), working memory for digits (backward digit span), verbal working memory (months of the year backward), and spatial working memory (modified Corsi block tapping test; for more details about the sub-tests, see [48]). The tasks motor series, conflicting instructions, and Go/no Go were taken from the FAB, and the remaining ones were included to optimize the tool's sensitivity. In the original study, the IFS showed good internal consistency, sensitivity, 
and specificity. It discriminated healthy controls from patients with dementia, and between different types of dementia as well (AD and FTD). Performance on the IFS correlated with traditional executive measures, namely phonological fluency, Trail Making Test, and Wisconsin Card Sorting Test. Gleichgerrcht, Roca, Manes, and Torralva [44] observed that, compared to the FAB, the IFS shows stronger correlations with other executive measures and higher sensitivity and specificity for identifying executive dysfunction in AD and FTD. In another study [49], however, the (Chilean) IFS and the FAB were highly correlated $(r=.94)$ and did not differ in their ability to distinguish controls from patients with dementia of different etiologies. Hence, more comparisons are needed to determine whether or not the IFS can yield better results than the FAB. Other issues remain undetermined. First, normative values are currently unavailable for the IFS, and it is unknown how sociodemographic variables, such as age and education, affect performance. Neuropsychological tests can be influenced by these variables [19,37,50-53], and it is important that they are considered when interpreting whether a score reflects impairment or not. Second, the IFS is available in English, Spanish [48] and Chilean [49], but adaptations for other cultural backgrounds are lacking. These will be critical before it can be widely used, as previously observed for other screening tools $[19,54]$. Third, preliminary evidence indicates that the IFS is sensitive to executive dysfunction in $\mathrm{AD}[44,48]$, but a follow-up of these findings would be enlightening. A comparison of $\mathrm{AD}$ patients and controls across each of the sub-tests has not been conducted, and a cut-off has not been generated. Moreover, the available evidence does not explore the possible role of depression symptoms, and the comparison between controls and AD patients by Torralva et al. [48] is limited by the fact that the two groups were not age-matched. 
The goals of the present study were to adapt the IFS for the Portuguese population, to collect normative data from a cognitively healthy sample, to examine the impact of sociodemographic variables on performance, and to investigate its clinical utility in $\mathrm{AD}$ (discriminant validity). We hypothesized that performance would be positively influenced by education and negatively influenced by age, and impaired in $\mathrm{AD}$ as compared to healthy controls. We also compared the IFS and the FAB regarding sensitivity and specificity. To investigate concurrent validity, we analyzed correlations with well-established and ecological measures of EF, namely the Stroop test [55], Clock Drawing Test [56], and the Zoo Map Test and Rule Shift Card of the BADS [32].

\section{Materials and Methods}

\section{Participants}

A total of 204 participants were included in the normative study (143 female), varying widely in age and education (see Table 1). Age ranged between 20 and 85 years $(M=44.98$; $S D=21.23)$, and education ranged between 3 and 21 years $(M=10.52 ; S D=4.82)$. All participants were European Portuguese native speakers, living in rural, suburban, and urban regions of Portugal, mainly northern. To ensure that they were cognitively healthy, participants were interviewed by a psychologist and were included only if they were autonomous in daily living activities, and had no history of alcoholism/substance abuse, brain injury, neurological/psychiatric conditions, or other conditions which may impact on cognition. Normal performance on the MMSE [34,57] was required (the Portuguese cut-offs were used: 22, 24 and 27 for 0-2, 3-6 and > 12 years of education, respectively [52]). Eleven of the initial 215 participants who volunteered to take part were excluded. The final sample 
scored high on the MMSE $(M=29.15 ; S D=1.19$; range for participants aged $20-44$ years $=$ $27-30,45-64$ years $=24-30,>65$ years $=25-30)$.

The AD sample consisted of 21 patients (14 female) recruited through the Centro Hospitalar de Entre o Douro e Vouga, Portugal. The diagnosis of "Probable AD dementia with evidence of the AD pathophysiological process" was confirmed by experienced neurologists based on the criteria of the Institute of Neurological and Communicative Disorders and Stroke and Alzheimer's Disease and Related Disorders Association (NINCDS-ADRDA [58]). All patients underwent detailed neurological, neuropsychological and structural neuroimaging (magnetic resonance imaging or computerized axial tomography) examinations. In two cases, the disease was further characterized with a cerebrospinal fluid analysis (amyloid-beta protein deposition and both total tau and phosphorylated tau). According to the Global Deterioration Scale [59] (Portuguese version [60]), all patients had early dementia (stage 4), showing clear-cut deficits on clinical interview and difficulties dealing with challenging tasks/situations, but being still able to live with no or minimal assistance. At the moment of testing, 12 patients were medicated with $\mathrm{AD} /$ memory-related medication (donezepil, $\mathrm{n}=4$; memantine, $\mathrm{n}=3$; rivastigmine, $\mathrm{n}=2$; Ginkgo Biloba, $\mathrm{n}=2$; vinpocetina, $\mathrm{n}=1$ ), 8 were taking antidepressants and benzodiazepines, and 1 was taking neuroleptics. No comorbid conditions were identified, apart from mild heart disease in 2 patients (patients with conditions such as stroke, traumatic brain injury, alcoholism and substance abuse, infections or major psychiatric disorders were not included). The patients performed 23.33 on the MMSE $(S D=3.84$; range $=14-30$; for similar scores on patients with $\mathrm{AD}$, see $[44,45,46])$. Mean age for the $\mathrm{AD}$ sample was 74.57 years $(S D=4$; range $=65-$ $85)$ and mean education was 3.67 years $(S D=0.48$; range $=3-6)$. This education level is lower than the one observed in several studies [31,44,47,61-63], but it is representative of the 
majority of Portuguese elderly population. According to Censos 2011 [64], the majority of people over 65 years in Portugal completed only what is currently known as $1^{\text {st }}$ Cycle of Basic Education, which corresponds to 4 years $(67.27 \%, 62.65 \%$, and $56.80 \%$ of the people aged 65-69 years, 70-74 years, and 75-79 years, respectively). Depression symptoms were controlled for using the Geriatric Depression Scale [65] (Portuguese version [66]). As indicated in Table 3, the patients' average score on this scale was 9.9 (scores $\geq 11$ are suggestive of depression $[65,66])$. Patients who scored above the cut-off on this scale were not excluded $(n=10)$ on the basis of evidence that depression symptoms are highly prevalent in early $\mathrm{AD}[67,68,69]$ and that common neuropathological mechanisms may underlie the two conditions $[70,71]$. This study was approved by the ethics committee of Centro Hospitalar de Entre o Douro e Vouga, and performed in accordance with the 1964 Declaration of Helsinki and its later amendments. Informed consent was obtained from all participants.

Table 1 here

\section{Materials}

Participants were tested in a single session conducted by a psychologist experienced in neuropsychological assessment. Healthy participants underwent a clinical interview to collect sociodemographic and clinical information, including current health status and medical history, after which they completed the MMSE and the IFS, recently translated and adapted for the Portuguese population by our group. The IFS was first translated into Portuguese from the original Spanish and English versions [48] by two independent researchers; both researchers were Portuguese native speakers, and they were proficient in English and fluent in reading Spanish. These translations were compared and the inconsistencies solved. A 
preliminary version was discussed regarding content validity with several experts in neuropsychological assessment. To make the IFS appropriate for the Portuguese linguistic/cultural context, the Proverbs sub-test was adapted to include only items frequently used in Portugal: "Cão que ladra não morde" ("Dog that barks does not bite", same as in the original Spanish version); "Mais vale um pássaro na mão do que dois a voar" ("A bird in the hand is worth two in the bush", same as in the original English version); and "Mais vale prevenir do que remediar" ("Better safe than sorry", new item). After reaching consistency for all verbal instructions and performing pilot administrations, the final version was produced. The Portuguese-IFS is freely available from the authors upon request.

Concerning AD patients, a comprehensive neuropsychological assessment was conducted. In addition to the MMSE and the IFS, they completed the Global Deterioration Scale and the Geriatric Depression Scale, as mentioned above. Furthermore, they completed classical measures of EF, namely the FAB [36] (Portuguese version [19]) and the Stroop test [55], as well the Clock Drawing Test [56]. They also completed two tests of the BADS [32], a battery designed to assess EF in a more complex and ecological way: the Zoo Map Test, which assesses the ability to formulate and implement a plan, and the Rule Shift Card, which assesses perseverative tendencies and mental flexibility.

To analyze the clinical utility of the IFS in $\mathrm{AD}$, the patients were compared with a sample of 21 controls, who were selected from the healthy normative sample. To guarantee comparability, care was taken to match patients and control regarding age, education, and magnitude of depression symptoms (for details about the background and neuropsychological characteristics of patients and controls, see Table 3). The two groups underwent the same neuropsychological assessment battery.

\section{Statistical analysis}


To examine the influence of sociodemographic variables (age, education and gender) and global cognitive functioning (MMSE) on the IFS scores, a stepwise multiple linear regression analysis was conducted on the normative sample (healthy participants, $N=204$ ). Internal consistency was investigated with Cronbach's alpha coefficient. Differences between $\mathrm{AD}$ patients and matched controls regarding performance on the IFS and FAB (total scores and subscores) and on the other executive tests were explored with independent samples Student's t-tests. An analysis of covariance (ANCOVA) was conducted, including education and MMSE scores as covariates, to determine whether group differences in the IFS remain significant after partialling out variability in these confounds. A receiver operating characteristic (ROC) curve analysis was carried out to examine the IFS diagnostic/discriminatory accuracy, and to determine the optimal cut-off to differentiate patients from controls. The same analysis was computed on the FAB scores and results were compared. To investigate concurrent validity with other executive tests, Pearson correlations were computed. Partial correlations controlling for age, education and MMSE were also computed to ensure that the identified associations between executive tests are not artifacts of variability in these confounds. All effects were considered significant at $p<.05$ (uncorrected); we report exact $p$ values (unless they are $<.001$ ) and effect sizes in the text. Significant differences at a more stringent level of $p<.001$ are signaled in the tables ${ }^{1}$.

\footnotetext{
${ }^{1}$ Bonferroni adjustments were not used as that they may be very conservative, particularly when the number of comparisons is large and when the tests are not independente $[72,73]$.
} 


\section{Results}

\section{Normative values and the role of sociodemographic variables}

Table 2 depicts the mean values and standard deviations for the total IFS scores as a function of age and education. The mean IFS score observed across the entire sample was $23.49(S D=4.13)$. Age, gender, number of years of education, and MMSE score entered the multiple linear regression model as predictors, and the total IFS score as dependent variable. The resulting model excluded gender, and it included age, education and MMSE as significant predictors, which were able to explain, altogether, $52,7 \%$ of the total variance [adjusted $R^{2}=$ $.53, F(3,203)=74.42, p<.001]$. Education was the strongest predictor, with longer education predicting higher IFS scores $[\beta=.432, t=6.76, p<.001]$, and it was followed by age and MMSE. Advancing age predicted lower IFS scores $[\beta=-.232, t=-3.90, p<.001]$, and better performance on the MMSE predicted higher IFS scores $[\beta=.201, t=3.41, p=.001]$. To summarize, the IFS total score was higher in younger and more educated individuals with higher performance on the MMSE.

The Portuguese-IFS showed acceptable internal consistency, as indicated by a Cronbach's alpha coefficient between subscores of .69.

Table 2 here

\section{The utility of the IFS in Alzheimer's disease}

The performance of AD patients and matched healthy controls on EF tests is described

in Table 3. Independent samples t-tests revealed that the patients underperformed controls on the traditional standardized measures of EF, namely the Stroop test and the Clock Drawing Test, as well as on the more ecological tests taken from the BADS, the Zoo Map Test (raw 
score and execution time of Condition 2) and the Rule Shift Card (errors in Condition 2). The patients also had difficulties on the FAB, the most frequently used screening tool of EF. Thus, the patients sampled here had significant executive impairments, a result consistent with previous literature on $\mathrm{AD}[15-17,24,25,27,29]$.

Discriminant validity. To examine whether the IFS is sensitive to executive dysfunction in $\mathrm{AD}$, we first compared the total scores across groups. As can be seen in Table 3, the patients' scores were significantly worse (11.38) than controls' (20.1), with the patients scoring 8.72 points lower than controls, $F(1,41)=30.22, p<.001, \eta_{\mathrm{p}}{ }^{2}=.43$ (this difference was numerically similar to the one reported by Torralva et al. [48], 7.3 points). This effect was further confirmed by an ANCOVA with education and MMSE as covariates, $F(1,38)=$ 4.91, $p=.03 ; \eta_{\mathrm{p}}^{2}=.11$ (education and MMSE were included as covariates because these variables correlate with the IFS total score, $r=.33, p=.04$ and $r=.73, p<.001$, respectively). These results indicate that the IFS presents good discriminant validity in AD. The fact that the differences between groups were not reducible to differences in the MMSE suggests that the IFS is selectively tapping on the patients' executive difficulties, and not only on their general cognitive impairment.

To examine possible differences in performance across sub-tests, we compared the two groups on their scores for each individual task. These results are presented in Figure 1, which for comparison purposes also presents scores for the FAB sub-tests. Independent samples t-tests showed that $\mathrm{AD}$ patients performed significantly worse than controls on the three sub-tests which are common to the IFS and the FAB, as well as on four out of the five sub-tests which are specific to the IFS: motor series $[t(40)=-4.005, p<.001]$, conflicting instructions $[t(40)=-3.55, p=.001]$, Go/no go $[t(40)=-3.38, p=.002]$, verbal working memory $[t(40)=-2.96, p=.006]$, spatial working memory $[t(40)=2.40, p=.001]$, proverbs 
$[t(40)=-2.71, p=.01]$, and Hayling test $[t(40)=-4.67, p=.02]$. Thus, only one sub-test of the IFS was insensitive to group differences, the backward digit span $(p=.29)$. Concerning the sub-tests specific to the FAB, only similarities discriminated AD patients from controls $[t(40)=-5.43, p<.001]$. Differences were non-significant for lexical fluency and prehension behaviour $(p \mathrm{~s}=.12$ and .32 , respectively).

Table 3 here

Figure 1 here

Diagnostic accuracy. To further investigate how the IFS discriminated AD patients from controls, a ROC curve analysis was carried out on the IFS total score between the two groups. This analysis generated an optimal cut-off score of 17 points, with sensitivity of $76.2 \%$ and specificity of $81 \%$. The area under the curve $(\mathrm{AuC})$ was $.88, \mathrm{CI}=[.78, .90], S E=$ .052. This level of specificity satisfies The Ronald and Nancy Reagan Research Institute of the Alzheimer's Association's [74] recommendations for ideal biomarkers of AD (no less than $80 \%$ ), and the obtained level of sensitivity approaches the recommendations as well (also $80 \%$ ). It is noteworthy that these results were attained with a purely behavioral, simple, quick and inexpensive tool as the IFS.

There were no noticeable differences between the IFS and the FAB regarding diagnostic accuracy, as indicated by a ROC curve analyses on the FAB total score. The area under the curve was highly similar to the one found for the IFS, .87, CI $=[.76, .98], S E=$ .057 . A cut-off of 13 was generated, with sensitivity of $81 \%$ and specificity of $71 \%$. The fact that the IFS and the FAB sub-tests partially overlap may contribute to explain this null result, 
but note also that the original hypothesis of the authors was that by introducing new sub-tests in the IFS (and not including some of the FAB ones) there would be gains in terms of sensitivity and specificity [48].

Figure 2 here

Concurrent validity. Table 4 presents the correlation coefficients, as well as partial coefficients, which were calculated taking into account sociodemographic variables, specifically age and education (and performance on the MMSE, in the case of correlations with other measures of EF). As can be seen, significant correlations were found between the IFS and other measures of EF, namely Clock Drawing Test, Zoo Map Test (raw score and execution time in condition 2), and Rule Shift Card (errors in conditions 1 and 2). These were lower when possible confounds were partialled out, but they were still significant (except for execution time in condition 2 of Zoo Map Test, and for errors in condition 1 of Rule Shift Card). These results indicate that the IFS has good concurrent validity. Replicating previous findings, the IFS also correlated with performance on the MMSE [48,49]. Importantly, no associations were found with the magnitude of the depression symptoms. For comparison purposes, the same analyses were computed for the FAB scores: it also correlated with other measures of EF (Clock Drawing Test, raw score and execution time in condition 2 of Zoo Map Test, and errors in condition 1 and 2 of Rule Shift Card) and MMSE, but not with depression.

Table 4 here 
Comparing the IFS and the FAB. As mentioned above, AD patients scored lower than controls in both the IFS and the FAB, and the diagnostic accuracy of the two tests was similar, as indicated by similar areas under the curve in the ROC curve analyses. With respect to concurrent validity, both tests correlated with a number of other EF measures, and they also correlated strongly with each other, $r=.83$ (for a high correlation between the IFS and the FAB, $r=.94$, see also Ihnen et al. [49]). Thus, for the participants sampled here, both the IFS and the FAB showed evidence of good validity and diagnostic accuracy. Concerning sub-tests, though, while $88 \%$ of the IFS tasks discriminated patients from controls ( 7 out of 8 ), only $67 \%$ of the FAB tasks did so (4 out of 6 ). Thus, the IFS includes a higher proportion of sensitive sub-tests than the FAB.

\section{Discussion}

To provide a brief and simple tool for evaluating executive dysfunction in neurodegenerative conditions, Torralva et al. [48] recently designed the IFS. The present study revealed four main findings. First, after translating and adapting the IFS for the Portuguese population, we collected normative values from healthy individuals and observed that performance is influenced by age and education. Second, appropriate internal consistency was obtained, as measured by Cronbach's alpha in healthy participants. Third, we showed that the IFS is useful to inspect executive dysfunction in AD: patients' total scores were lower than controls' (discriminant validity); a cut-off of 17 produced a good AuC and an optimal balance between sensitivity and specificity (diagnostic accuracy); the patients presented impaired performance for all IFS sub-tests, except for backward digit span; and the IFS correlated with other well-established measures of EF (concurrent validity). Fourth, in 
comparison with the FAB, more sub-tests of the IFS were sensitive to executive dysfunction in AD. These findings are discussed next.

As expected, performance on the IFS decreased as a function of age and increased as a function of education. The influence of age and education on performance on neuropsychological tests, namely on screening tools, has been consistently reported in the literature $[8,56,75,76]$. For instance, similar findings were previously observed for the FAB $[19,37,38]$ and for the two most frequently used screening tools of general cognition, the MMSE [18,52,76,77] and the Montreal Cognitive Assessment [51,53,78-80]. To our knowledge, our study is the first one looking at the role of these sociodemographic variables in the context of the IFS. These results highlight that, when using the IFS in research and clinical contexts, it is crucial to interpret individual or group scores taking into account age and education level. In fact, this is a well-established practice in cognitive and neuropsychological testing, particularly in what respects to age $[51,52,81]$. Concerning the possible mechanisms underlying these effects, it is known that advancing age is associated with decline in EF $[12,81,82]$, and this may explain why older participants scored lower than younger ones on the IFS. That lower education may be associated with worse scores in executive performance is consistent with previous evidence: Pavão Martins et al. [83], for instance, found that older adults with lower education score lower than those with higher education in several EF tasks (Trail Making Test, Symbol Search, Matrix reasoning, Semantic and phonemic verbal fluencies, Stroop test; digit span); note that possible confounds were excluded, such as lack of health care or extreme poverty, suggesting that the effect of education is a direct one. Having access to education may increase familiarity with evaluation contexts, as well as increase practice on tasks similar to the ones included in neuropsychological tests, which may explain the positive effects we uncovered. We have also 
found that the MMSE scores predict performance on the IFS. This is in line with previous research on the relationship between general cognitive functioning and performance on EF measures $[19,44,48,49,84]$. It may partly reflect the fact that the MMSE taps on executive processes to a significant extent (e.g., sub-tests attention and calculation, language, and 3-stage command).

That the IFS presented evidence of acceptable internal consistency lends credence to earlier studies with other versions of this tool, namely English, Spanish and Chilean [44, 48,49], and extends their findings to the Portuguese version. This suggests that the psychometric properties of the IFS are robust across languages and cultural settings. Thus, we consider that it can be used with confidence in the Portuguese population.

Regarding the utility of the IFS to evaluate executive dysfunction in AD, both the total score and all subscores individually (except for backward digit span) were effective at discriminating patients from healthy controls. These results further confirm the findings by Torralva et al. [48]. They also add to the findings by Gleichgerrcht et al. [44]: as in the present study, they observed that $\mathrm{AD}$ patients perform worse than age- and education-matched controls on the IFS, but possible differences in sensitivity across sub-tests were not considered. Therefore, our findings contribute to establish the clinical value of the IFS in AD by showing a reduction in total scores in a new sample of patients, and by showing for the first time that most IFS sub-tests are sensitive to EF difficulties in this disease. Furthermore, in previous studies depression symptoms were not evaluated [48], or they were higher in the clinical sample than in controls [44], making it difficult to discern whether patients' reductions relative to controls are a specific effect of the disease or an effect of depression symptoms. This issue is clarified here: patients and controls were matched for the magnitude of depression symptoms and, crucially, we observed that performance on the IFS and 
depression symptoms are not correlated. In terms of diagnostic accuracy, the optimal cut-off revealed by our ROC curve analysis was 17 , which is similar to the one found recently by Ihnen et al. [49] for the Chilean version of the IFS (18 points), in a study including health controls and patients with several types of dementia. This cut-off is lower than the one reported in the original study (25 points), though [48]. This discrepancy is probably related to differences in education levels between samples. While participants in Torralva et al.'s study attended school for around 15 years, in our sample they attended school for 4 years only. This explanation is in line with the positive association we found between education and performance on the IFS. These differences are further evidence that accuracy in the interpretation of scores on this battery depends on considering the moderating role of sociodemographic factors.

One of the goals of the present study was to investigate the concurrent validity of the IFS. Significant correlations were uncovered between scores on this battery and scores on several other measures of EF, specifically Clock Drawing Test, Zoo Map Test (Condition 2) and Rule Shift Card. These results attest the concurrent validity of the IFS, and they extend the findings of the original study [48], in which correlations were found with different EF measures, phonological fluency, Trail Making Test, and Wisconsin Card Sorting Test (see also [44]). Regarding the Clock Drawing test, however, note that impairments in AD reflect executive dysfunction, but they may also reflect visuospatial and constructional problems to some extent [85]. It is noteworthy that two of the tests of EF we used, the Zoo Map Test and the Rule Shift Card, were taken from the BADS, a battery designed to include ecologically valid tasks which can predict daily life difficulties more effectively than standardized/conventional measures $[17,86]$. Finding that a standardized screening tool like the IFS correlates with ecological measures of EF is highly relevant in terms of its clinical 
value - it suggests that this simple tool may provide information which is predictive of daily life functioning, even though it is brief and easy to administer. In the future it will be important to determine whether the IFS is also predictive of behavioral and emotional symptoms, as assessed using tools such as the Frontal Behavioral Inventory [87].

The IFS was developed in an attempt to provide a more sensitive index of executive dysfunction than the FAB, which has become the most extensively used screening tool of EF in the last years. We observed that they both have good discriminant validity, diagnostic accuracy, and concurrent validity. Our results confirm previous research showing that the FAB is sensitive to executive dysfunction in $\mathrm{AD}[88,89]$ and correlates with other measures of EF $[19,38,39,41]$. Nevertheless, the fact more sub-tests of the IFS ( 7 out of $8,88 \%$ ) than of the FAB (4 out of $6,67 \%$ ) discriminated AD patients from controls suggests that the IFS may provide more fine-grained information about the patients' difficulties. Additionally, in comparison with the FAB, the IFS may be especially useful when testing younger and more educated individuals because it is less prone to ceiling effects. While highly educated younger participants were shown to perform at maximum levels in the FAB [19,37], the same was not found here for the IFS (see results; an inspection of Table 2 suggests that floor effects are also unlikely, even for older and lower educated individuals). In contrast to Gleichgerrcht et al. [44], though, we did not find advantages of the IFS over the FAB in terms of diagnostic accuracy and strength of the correlations with other EF measures. Additionally, in line with Ihnen et al. [49], we found a very high correlation between the IFS and FAB, $r>.8$, suggesting that they cover the same underlying processes to a large extent. Hence, the issue of the relative clinical usefulness of the two tests calls for more detailed exploration in the future. The same holds true regarding whether they are sensitive to executive dysfunction at very early pathological stages, such as in mild cognitive impairment. Preliminary evidence 
indicates that the FAB may be able to differentiate amnestic mild cognitive impairment and early stage AD [90], but evidence for this on the IFS is lacking, as are comparisons between the two tools and with healthy controls. Another relevant question will be to determine whether performance in brief tools like these can distinguish a frontal variant of AD from typical AD, which may involve distinct clinical and pathological features [91].

In conclusion, the results of the present study establish that (a) performance on the IFS is influenced by sociodemographic variables, notably age and education, and that (b) this screening tool is effective at detecting executive dysfunction in AD. They suggest that the IFS can provide valuable information for the diagnosis of this disease, and set the stage for future studies to determine whether it is also suitable to monitor its progression over time. The clinical value of this tool was further confirmed by correlations with other measures of executive functioning, namely with measures related to real life situations. In addition, the validated Portuguese version of the IFS, which we make available here, and the normative data from a healthy sample, will contribute greatly to improve the confidence and accuracy in the utilization of this tool with Portuguese speaking patients in research and clinical contexts.

Conflict of interests: The authors declare that they have no conflict of interest. 


\section{Acknowledgments}

This work was conducted at the Faculty of Psychology and Education, University of Porto,

Portugal. It was supported by grants from the Portuguese Foundation for Science and Technology (to C.F.L. and S.G.V.).

We owe our thanks to Joana Pais, Ph.D., for help in recruiting patients, and to Universidade Sénior da Foz, for help in recruiting healthy participants. 


\section{References}

[1] Alvarez JA, Emory E (2006) Executive function and the frontal lobes: a meta-analytic review. Neuropsychol Rev 16, 17-42.

[2] Baddeley A (2002) Fractionation of the Supervisory System. In Principals of frontal lobe function, Knight RT, Struss DT, eds. Oxford University Press, New York, pp. 246-261

[3] Duke LM, Kaszniak AW (2000) Executive Control Functions in Degenerative Dementias: A comparative Review. Neuropsychol 10,75-99.

[4] Elliot R (2006) Executive functions and their disorders. Br Med Bull 65, 49-59.

[5] Funahashi S (2001) Neuronal mechanisms of executive control by the prefrontal cortex. Neurosci Res 39, 147-165.

[6] Packwood P, Hodgetts HM, Tremblay S (2011) A multiperspective approach to the conceptualization of executive functions. J Clin Exp Neuropsychol 33, 456-470.

[7] Burguess P (1997) Theory and Methodology in Executive Function Research. In Methodology of Frontal and Executive Function, Rabbit P, ed. Taylor \& Francis, United Kingdom, pp. 79-108

[8] Lezak MD, Howieson DB, Loring DW (2004) Neuropsychological assessement, 4th edn. Oxford University Press, London.

[9] Andrewes D (2001) Neuropsychology: From Theory to Practice. Psychology Press, New York. 
[10] Kolb B, Wishaw IQ (2003) Fundamentals of Human Neuropsychology, 5th edn. Worth Publishers, New York.

[11] Sowell ER, Thompson PM, Tessner KD, Toga AW (2001) Mapping continued brain growth and gray matter density reduction in dorsal frontal cortex: Inverse relationships during post-adolescent brain maturation. $J$ Neurosci 22, 8819-8829.

[12] Allain P, Nicoleau S, Pinon K, Etcharry-Bouyx F, Barré J, Berrut G, Dubas F, Le Gall D (2005) Executive functioning in normal aging: A study of action planning using the Zoo Map Test. Brain Cogn 57, 4-7.

[13] Amieva H, Phillips L, Della Sala S (2003) Behavioral dysexecutive symptoms in normal aging. Brain Cogn 53, 129-132.

[14] Amieva H, Lafont S, Rouch-Leroyer I, Rainville C, Dartigues JF, Orgogozo JM, Fabrigoule C (2004a) Evidencing inhibitory deficits in Alzheimer Disease through interference effects and shifting disabilities in Stroop Test. Arch Clin Neuropsychol 19, 791-803.

[15] Amieva H, Phillips LH, Della Salla S, Henry JD (2004b) Inibitory functioning in Alzheimer Disease. Brain 127, 949-964.

[16] Amieva H, Lafont S, Auriacombe S, Le Carret N, Dartigues JF, Orgogozo J-M, Fabrigoule C (2002) Inhibitory Breakdown and Dementia of the Alzheimer Type: A General Phenomenon? J Clin Exp Neuropsychol 24, 503-516.

[17] Espinosa A, Alegret M, Boada M, Vinyes G, Valero S, Martínez-Lage, P, Peña-Casanova J, Becker JT, Wilson B, Tárraga, L (2008) Ecological assessment of executive functions in mild cognitive impairment and mild Alzheimer's disease. J Int Neuropsychol Soc $15,751-757$. 
[18] Anderson KE (2004) Behavioral disturbances in Parkinson's disease. In Dialogues in Clinical Neuroscience (vol. 6-3), Macher JP, ed. Les Laboratoires Servier, France, pp. $323-333$.

[19] Lima C, Meireles LP, Fonseca R, Castro SL, Garret C (2008) The Frontal Assessment battery (FAB) in Parkinson's disease and correlations with formal measures of executive functioning. J Neurol 255, 1756-1761.

[20] Lima C, Garret C, Castro SL (2013) Not all sounds sound the same: Parkinson's disease affects differently emotion processing in music and in speech prosody. $J$ Clin Exp Neuropsychol 35, 373-392.

[21] Braaten AJ, Parsons TD, McCue R, Sellers A, Burns W (2006) Neurocognitive Differential Diagnosis of Dementing Diseases: Alzheimer's Dementia, Vascular Dementia, Frontotemporal dementia and Major Depressive Disorder. Int J Neurosci 116, 1271-1293.

[22] Mathias JL, Burke J (2009) Cognitive Functioning in Alzheimer's and Vascular Dementia: A Meta-Analysis. Neuropsychol 23, 411-423.

[23] Tartaglia MC, Zhang Y, Racine C, Laluz V, Neuhaus J, Chao L, Kramer J, Rosen H, Miller B, Weiner M (2012) Executive dysfunction in frontotemporal dementia is related to abnormalities in frontal white matter tracts. J Neurol 259, 1071-1080.

[24] Baudic S, Barba GD, Thibaudet MC, Smagghe A, Remy P, Traykov L (2006) Executive function deficits in early Alzheimer's disease and their relations with episodic memory. Arch Clin Neuropsychol 21,15-21.

[25] Bisiacchi P, Borella E, Bergamaschi S, Caretti B, Mondini S (2008) Interplay between memory and executive functions in normal and pathological aging. J Clin Exp Neuropsychol 30, $723-733$. 
[26] Cullen B, O’Neiil B, Evans JJ, Coen RF, Lawlor BA (2007) A review of screening tests for cognitive impairement. J Neurol Neurosurg Psychiatry 78, 790-799.

[27] Sgaramella TM, Borgo F, Mondini S, Pasini M, Toso V, Semenza C (2001) Executive Deficits Appearing in the Initial Stage of Alzheimer's Disease. Brain Cogn 46, 264-268.

[28] Clark LR, Schiehser DM, Weissberger GH, Salmon DP, Delis DC, Bondi MW (2012). Specific Measures of Executive Function Predict Cognitive Decline in Older Adults. $J$ Int Neuropsychol Soc 18, 118-127.

[29] Stokholm J, Vogel A, Gade A, Waldemar G (2006) Heterogeneity in Executive Impairment in Patients with very mild Alzheimer's Disease. Dement Geriatr Cogn Disord 22, 54-59.

[30] Balota DA, Tse CS, Hutchinson KA, Spieler DH, Duchek JM, Moris JC (2010) Predicting conversion to dementia of the Alzheimer's type in a healthy control sample: The power of errors in Stroop color naming. Psychol Aging 25, 208-218.

[31] Bangert AS, Balota DA (2012) Keep up the Pace: Declines in simple repetitive timing differentiates healthy aging from the earliest stages of Alzheimer's disease. $J$ Int Neuropsychol Soc 18, 1052-1063.

[32] Wilson BA, Alderman N, Burguess PW, Esmlie, H, Evans, JJ (1996) Behavioral Assessment of the Dysexecutive Syndrome, Thames Valley Test, United Kingdom.

[33] Stern RA, White T (2003) NAB administration, scoring and interpretation manual, Psychological Assessment Resources, Lutz.

[34] Folstein MF, Folstein SE, Mchugh PR (1975) Mini Mental State: a pratical method for grading the cognitive state of pacients for the clinician. J Psychiatr Res 12, 189-198. 
[35] Nasreddine ZS, Phillips NA, Bédirian V, Charbonneau S, Whitehead V, Collin I, Cummings JL, Chertkow H (2005) The Montreal Cognitive Assessment, MOCA: A brief screening Tool for mild cognitive impairment. J Am Geriatr Soc 53, 695-699.

[36] Dubois B, Slachevsky A, Litvan I, Pillon B (2000) The FAB: A frontal assessment battery at bedside. Neurol 55, 1621-1626.

[37] Appollonio I, Leone M, Isella V, Piamarta F, Consoli T, Villa ML, Forapani E, Russo A, Nichelli P (2005) The Frontal Assessment Battery (FAB): Normative values in an Italian population sample. Neurol Sci 26, 108-116.

[38] Benke T, Karner E, Delazer M (2013) FAB-D: German version of the Frontal Assessment Battery. J Neurol 260, 2066-2072.

[39] Cohen OS, Vakil E, Tanne D (2012) The frontal assessment battery as a tool for evaluation of frontal lobe dysfunction in patients with Parkinson disease. J Geriatr Psychiatry Neurol 25, 71-77.

[40] Oguro H, Yamaguchi S, Abe S, Ishida Y, Bokura H, Kobayashi S (2006) Differentiating Alzheimer's Disease from subcortical vascular dementia with the FAB test. $J$ Neurol 253,1490-1494.

[41] Rodrigues GR, Souza CP, Cetlin RS, de Oliveira DS, Pena-Pereira M, Ujikawa LT, Marques W Jr, Tumas V (2009) Use of the frontal assessment battery in evaluating executive dysfunction in patients with Huntington's disease. J Neurol 256, 1809-18015.

[42] Matsui H, Udaka F, Miyoshi T, Hara N, Tamura A, Oda M, Kubori T, Nishinaka K, Kameyama M (2009) Frontal Assessment Battery and Brain Perfusion Image in Parkinson's Disease. J Geriatr Psychiatry Neurol 19, 41-45. 
[43] Castiglioni S, Pelati O, Zuffi M, Somalvico F, Marino L, Tentorio T, Franceschi M (2006) The Frontal Assessment Battery does not differentiate Frontotemporal Dementia from Alzheimer's Disease. Dement Geriatr Cogn Disord 22, 125-131.

[44] Gleichgerrcht E, Roca M, Manes F, Torralva T (2011) Comparing the clinical usefulness of the Institute of Cognitive Neurology (INECO) Frontal Screening (IFS) and the Frontotemporal Assessment Battery (FAB) in frontotemporal dementia. $J$ Clin Exp Neuropsychol 33, 997-1004.

[45] Lipton AM, Ohman KA, Womack KB, Hynan LS, Ninman ET, Lacritz LH (2005) Subscores of the FAB differentiate frontotemporal lobar degeneration from AD. Neurol 65, 726-731.

[46] Boban M, Malojcić B, Mimica N, Vuković S, Zrilić I (2012) The frontal assessment battery in the differential diagnosis of dementia. J Geriatr Psychiatry Neurol 25, 201-207.

[47] Chapados C, Petrides M (2013) Impairment Only on the Fluency Subtest of the Frontal Assessment Battery After Prefrontal Lesions. Brain 136, 2966-2978.

[48] Torralva T, Roca M, Gleichgerrcht E, López P, Manes F (2009) INECO Frontal Screening (IFS): A brief, sensitive, and specific tool to assess executive functions in dementia. J Int Neuropsychol Soc 15, 777-786.

[49] Ihnen J, Antivilo A, Munoz-Neira C, Slachevsky A (2013) Chilean version of the INECO Frontal Screening (IFS-Ch). Dement Neuropsychol 7, 40-47.

[50] Foss MP, Carvalho do Vale FS, Speciali JG (2005) Influência da escolaridade na avaliação neuropsicológica de idosos [Influence of education on the neuropsychological assessment of the elderly]. Arq Neuropsiquiatr 1, 119-126.

[51] Freitas S, Simões M, Alves L, Santana I (2012) Montreal Cognitive Assessment: Influence of Sociodemographic and Health Variables. Arch Clin Neuropsychol 27, 165-175. 
[52] Morgado J, Rocha CS, Maruta C, Guerreiro M, Martins IP (2009) Novos valores normativos do Mini-Mental State Examination [New normative values for the Mini-Mental State Examination]. Sinapse 9, 10-16.

[53] Costa AS, Fimm B, Friesen P, Soundjock H, Rottschy C, Gross T, Eitner F, Reich A, Schulz JB, Nasreddine ZS, Reetz K (2012) Alternate-Form Reliability of the Montreal Cognitive Assessment Screening Test in a Clinical Setting. Dement Geriatr Cogn Disord $33,379-384$.

[54] Correia CC, Lima F, Junqueira F, Campos MS, Bastos O, Petribú K, Laks J, Galvin JE (2011) AD8-Brazil: cross-cultural validation of the ascertaining dementia interview in Portuguese. J Alzheimer Dis, 27 177-185.

[55] Stroop JR (1936) Studies of interference in serial verbal reactions. J Exp Psychol 18, 643-662.

[56] Shulman K (2000) Clock-drawing: is it the ideal cognitve screening test? Int J Geriatr Psychiatr 15, 548-561.

[57] Guerreiro M, Silva AP, Botelho MA et al (1994). Adaptação à população portuguesa da tradução do "Mini Mental State Examination" (MMSE) [Portuguese Adaptation of the Mini Mental State Examination]. Revista Portuguesa de Neurologia 9, 9-10.

[58] McKhann GM, Knopman DS, Chertkow H, Hyman BT, Jack CR Jr, Kawas CH, Klunk WE, Koroshetz WJ, Manly JJ, Mayeux R, Mohs RC, Morris JC, Rossor MN, Scheltens P, Carrillo MC, Thies B, Weintraub S, Phelps CH (2011) The diagnosis of dementia due to Alzheimer's disease: Recommendations from the National Institute on Aging and the Alzheimer's Association workgroup. Alzheimer's Dement 7, 1-7.

[59] Reisberg B, Ferris SH, Leon, MJ, Crook T (1982) The Global Deterioration Scale (GDS) for assessment of primary degenerative dementia. Am J Psychiatry 139, 1136-1139. 
[60] Leitão O, Nina A, Monteiro I (2007) Escala de Deterioração Global [Global Deterioration Scale. Tradition and Organization]. In Escalas e Testes na Demência [Scales and tests in dementia], Mendonça, A, Guerreiro, M, eds. Novartis, Lisboa, pp. 9-13

[61] Clemént F, Belleville S, Gauthier S (2008) Cognitive complaint in mild cognitive impairment and Alzheimer's disease. J Int Neuropsychol Soc 14, 222-32.

[62] Perri R, Koch G, Carlesimo GA, Serra L, Fadda L, Pasqualetti P, Pettenati C, Caltagirone C (2005) Alzheimer's disease and frontal variant of frontotemporal dementia: A very brief battery for cognitive and behavioural distinction. J Neurol 252, 1238-1244.

[63] Mussico M, Palmer K, Salamone G (2009) Predictors of progression of cognitive decline in Alzheimer's disease: the role of vascular and sociodemographic factors. $J$ Neurol 256, $1288-1295$.

[64] Statistics Portugal (2012) Censos 2011: Resultados Definitivos - Portugal. [Censos 2011: Definitive Results - Portugal]. Instituto Nacional de Estatística, Lisboa.

[65] Yesavage JA, Brink TL, Rose TL (1983) Development and validation of a geriatric depression screening scale: a preliminary report. J Psychiatr Res 17: 37-49.

[66] Barreto J, Leuschner A, Santos F, Sobral M (2007) Escala de depressão geriátrica [Geriatric Depression Scale]. In: Escalas e testes na demência [Scales and tests of dementia], Mendonça M, Guerreiro A, eds. Novartis, Lisboa, pp. 65-68.

[67] Green RC, Cupples LA, Kurz A, Auerbach S, Go R, Sadovnick D, Duara R, Kukull WA, Chui H, Edeki T, Griffith PA, Friedland RP, Bachman D, Farrer L (2003) Depression as a risk factor for Alzheimer Disease. The Mirage Study. Arch Neurol 60, 753-759.

[68] Lee HB, Lyketsos CG (2003) Depression in Alzheimer's disease: heterogeneity and related issues. Biol Psychiatry 54, 353-362. 
[69] Mondrego PJ, Fernandez J (2004) Depression in patients with mild cognitive impairment increases the risk of developing dementia of the Alzheimer type: A prospective cohort study. Arch Neurol 61, 1290-1293.

[70] Aznar S, Knudsen GM (2011) Depression and Alzheimer's Disease: Is Stress the Initiating Factor in a Common Neuropathological Cascade? J Alzheimer Disease 23, 177-193. [71] Caraci F, Copani A, Nicoletti F, Drago F (2010). Depression and Alzheimer's disease: Neurobiological links and common pharmacological targets. Eur J Pharmacol 10, 64-71.

[72] Adbi H (2007). The Bonferroni and Sidák Corrections for Multiple Comparisons. In Encyclopedia of Measurement and Statistics, Salkind N, ed., Sage, Thousand Oaks, pp. 103-107.

[73] Perneger T (1998) What's Wrong with Bonferroni Adjustments. Br Med J 316, $1236-1238$

[74] The Ronald and Nancy Reagan Research Institute of the Alzheimer's Association and National Institute on Aging Working Group AB (1998) Consensus Report of the Working Group on: "Molecular and Biochemical Markers of Alzheimer's Disease”. Neurobiol Aging 19, 109-116.

[75] Brodaty H, Kemp NM, Low LF (2004). Characteristics of the GPCOG, a screening tool for cognitive impairment. Int J Geriatr Psychiatry 19, 870-874.

[76] Mathuranath PS, Cherian JP, Mathew R, George A, Alexander A, Sarma SP (2007) Mini Mental State Examination and the Addenbrooke's Cognitive Examination: Effect of education and norms for a multicultural population. Neurol India 55, 106-110.

[77] Matallana D, Santacruz C, Cano C, Reyes P, Samper-Ternent R, Markides KS, Ottenbacher KJ, Reyes-Ortiz CA (2011) The relationship between educational level and 
Mini-Mental State Examination domains among older Mexican Americans. J Geriatr Psychiatry Neurol 24, 9-18.

[78] Gómez F, Zunzunegui MV, Lord C, Alvarado B, García A (2012) Applicability of the MoCA-S test in populations with little education in Colombia. J Int Geritric Psychiatry 28, 813-820.

[79] Rossetti HC, Lacritz, LH, Cullum CM, Weiner MF (2011) Normative data for the Montreal Cognitive Assessment (MoCA) in a population-based sample. Neurol, 77, $1272-1275$.

[80] Lu J, Li D, Li F, Wang F, Zuo X, Jia XF, Song H, Jia J (2011) Montreal Cognitive Assessment in Detecting Cognitive Impairment in Chinese Elderly Individuals: A Population-Based Study. J Geriatr Psychiatry Neurol 24, 184-190.

[81] Treitz FH, Heyder K, Daum I (2007) Differential Course of Executive Control Changes During Normal Aging. Aging Neuropsychol Cogn 14, 370-393.

[82] Van der Elst WV, Van Boxtel MPJ, Breukelen GJP, Jolles J (2006) The Stroop Color-Word Test: Influence of Age, Sex, and Education; and Normative Data for a Large Sample Across the Adult Age Range. Assessment 12, 62-79.

[83] Pavão Martins I, Maruta C, Freitas V, Mares I (2013). Executive performance in older Portuguese adults with low education. Clin Neuropsychol 27, 410-425.

[84] Swanberg MM, Tractenberg RE, Mohs R, Thai LJ, Cummings JL (2004) Executive Dysfunction in Alzheimer Disease. Archiv Neurol 61, 556-560.

[85] Cahn-Weiner D, Sullivan E, Shear P, Fama R, Lim K, Yesavage J, Tinklenberg J, Pfefferbaum A (1999). Brain Structural and Cognitive Correlates of Clock Drawing Performance in Alzheimer's Disease. J Int Neuropsychol Soc 5, 502-509. 
[86] Norris G, Tate RL (2000) The behavioural assessment of the dysexecutive syndrome (BADS): ecological, concurrent and construct validity. Neuropsychol Rehab 10, 33-45.

[87] Kertesz A, Nadkarni N, Davidson W, Thomas A (2000). The Frontal Behavioral Inventory in the Differential Diagnosis of Frontotemporal Dementia. J Int Neuropsychol Soc, 6, $460-468$.

[88] Iavarone A, Ronga B, Pellegrino L, Loré E, Vitaliano S, Galeone F, Carlomagno S (2004) The Frontal Assessment Battery: Normative data from an Italian sample and performances of patients with Alzheimer's disease and frontotemporal dementia. Funct Neurol 19, 191-195.

[89] Slachevsky A, Villapando JM, Sarazin M, Hahn-Barma V, Pillon B, Dubois B (2004) Frontal Assessment Battery and Differential Diagnosis of Frontotemporal Dementia and Alzheimer Disease. Arch Neurol 61, 1104-1107.

[90] Yamao A, Nagata T, Shinagawa S, Nukariya K, Ochiai Y, Kasahara H, Nakayama K (2011). Differentiation Between Amnestic-Mild Cognitive Impairment and Early-Stage Alzheimer's Disease Using the Frontal Assessment Battery Test. Psychogeriatrics 11, $235-241$

[91] Woodward M, Jacova C, Black S E, Kertesz A, Mckenzie I R, Feldman H, ACCORD investigator group (2010). Differentiating the frontal variant of Alzheimer's disease. Int $J$ Geriatr Psychiatry 25, 732-738.

Table 1. Demographic distribution of the healthy sample as a function of education and age $(N=204)$ 


\begin{tabular}{ccccc}
\hline & $20-44$ & $45-64$ & $>65$ & Total \\
\hline $1-4$ & $1(\mathrm{M} 1 / \mathrm{F} 0)$ & $16(\mathrm{M} 3 / \mathrm{F} 13)$ & $30(\mathrm{M} 11 / \mathrm{F} 19)$ & $47(\mathrm{M} 15 / \mathrm{F} 32)$ \\
$5-12$ & $36(\mathrm{M} 18 / \mathrm{F} 18)$ & $28(\mathrm{M} 8 / \mathrm{F} 20)$ & $10(\mathrm{M} 4 / \mathrm{F} 6)$ & $74(\mathrm{M} 30 / \mathrm{F} 44)$ \\
$>12$ & $61(\mathrm{M} 11 / \mathrm{F} 50)$ & $13(\mathrm{M} 2 / \mathrm{F} 11)$ & $9(\mathrm{M} 3 / \mathrm{F} 6)$ & $83(\mathrm{M} 16 / \mathrm{F} 67)$ \\
Total & $98(\mathrm{M} 30 / \mathrm{F} 68)$ & $57(\mathrm{M} 13 / \mathrm{F} 44)$ & $49(\mathrm{M} 18 / \mathrm{F} 31)$ & $204(\mathrm{M} 61 / \mathrm{F} 143)$ \\
\hline
\end{tabular}

Table 2. Mean total IFS scores for the healthy sample $(N=204)$ as a function of education and age. Standard deviations are given in parentheses. 


\begin{tabular}{|c|c|c|c|c|}
\hline \multirow[b]{2}{*}{ Education (years) } & \multicolumn{4}{|c|}{ Age (years) } \\
\hline & $20-44$ & $45-64$ & $>65$ & Total (all age levels) \\
\hline 1-4 (Primary) & 16.5 & $20.8(2.9)$ & $18.9(4.2)$ & $19.5(3.9)$ \\
\hline $\mathrm{SD}^{\mathrm{a}}$ & - & $18,16,15$ & $15,13,11$ & $16,14,12$ \\
\hline 5-12 (Middle and High) & $24.6(2.8)$ & $22.0(3.8)$ & $20.8(2.6)$ & $23.10(3.5)$ \\
\hline $\mathrm{SD}$ & $22,20,19$ & $18,16,14$ & $18,17,16$ & $20,18,16$ \\
\hline >12 (University) & $26.3(2.6)$ & $25.6(3.0)$ & $25.2(2.9)$ & $26.08(2.7)$ \\
\hline SD & $24,22,21$ & $23,21,20$ & $22,21,19$ & $23,22,21$ \\
\hline Total (all education levels) & $25.6(2.9)$ & $22.5(3.8)$ & $20.4(4.4)$ & $23.5(4.1)$ \\
\hline SD & $23,21,20$ & $19,17,15$ & $16,14,12$ & $19,17,15$ \\
\hline
\end{tabular}

${ }^{a}$ IFS values below $1 \mathrm{SD}, 1.5 \mathrm{SDs}$, and 2 SDs, respectively

Table 3. Background and neuropsychological characteristics of patients with Alzheimer's disease (AD) and healthy controls 


\begin{tabular}{|c|c|c|c|c|c|}
\hline \multirow[b]{2}{*}{ Measures } & \multicolumn{2}{|c|}{ AD Patients $(n=21)$} & \multicolumn{2}{|c|}{ Healthy Controls $(n=21)$} & \multirow[b]{2}{*}{$p$} \\
\hline & $M(S D)$ & Range & $M(S D)$ & Range & \\
\hline Age (years) & $74.57(4)$ & $65-85$ & $75.43(5.16)$ & $65-85$ & .55 \\
\hline Education (years) & $3.67(0.48)$ & $3-6$ & $4.48(3.18)$ & $2-15$ & .25 \\
\hline Gender (M:F) & $14: 7$ & - & $15: 6$ & - & \\
\hline MMSE (/30; cut-off 24) & $23.33(3.84)$ & $14-30$ & $28.24(1.3)$ & $26-30$ & $<.001$ \\
\hline GDS (/30) & $9.90(4.69)$ & $3-19$ & $8.62(5.2)$ & $3-18$ & .41 \\
\hline Clock Drawing Test (/5) & $2.33(1.32)$ & $0-5$ & $4.10(1.14)$ & $2-5$ & $<.001$ \\
\hline Stroop Test (interference index) & $4.67(9.9)$ & $-13-36$ & $10.29(6.46)$ & $1-23$ & .03 \\
\hline \multicolumn{6}{|l|}{ Zoo Map Test } \\
\hline \multicolumn{6}{|l|}{ Condition 1} \\
\hline Raw score (/8) & $2.86(2.87)$ & $0-8$ & $4.19(3.04)$ & $0-8$ & .15 \\
\hline Planning time (s) & $29.05(58.24)$ & $0-255$ & $36.83(38.06)$ & $1-147$ & .97 \\
\hline Execution time (s) & $158.81(70.26)$ & $53-311$ & $161.10(60.63)$ & $75-270$ & .91 \\
\hline \multicolumn{6}{|l|}{ Condition 2} \\
\hline Raw score (/8) & $5.67(2.46)$ & $0-8$ & $7.19(1.12)$ & $4-8$ & .01 \\
\hline Planning time (s) & $4.48(5.86)$ & $0-19$ & $5.67(9.31)$ & $0-42$ & .62 \\
\hline Execution time (s) & $123.76(57.1)$ & $48-232$ & $79.62(25.19)$ & $44-150$ & .002 \\
\hline \multicolumn{6}{|l|}{ Rule Shift Card } \\
\hline Errors Condition $1(/ 20)$ & $0.67(1.24)$ & $0-4$ & $.10(.3)$ & $0-1$ & .05 \\
\hline Errors Condition $2(/ 20)$ & $7.00(2.86)$ & $1-10$ & $2.52(2.58)$ & $0-10$ & $<.001$ \\
\hline $\operatorname{IFS}(/ 30)$ & $11.38(5.47)$ & $4.5-23$ & $20.10(4.78)$ & $11.5-26$ & $<.001$ \\
\hline FAB (/18) & $9.95(3.11)$ & $5-17$ & $15.0(3.03)$ & $8-18$ & $<.001$ \\
\hline
\end{tabular}

Note: $\mathrm{M}=$ male. $\mathrm{F}=$ female. MMSE = Mini-Mental State Examination. GDS = Geriatric Depression Scale. IFS = Institute of Cognitive Neurology Frontal Screening. FAB = Frontal Assessment Battery. Values in bold correspond to significant differences between $\mathrm{AD}$ patients and controls.

Table 4. Correlations between the IFS and FAB total scores, other measures of executive functioning, MMSE, and magnitude of depression symptoms 


\begin{tabular}{|c|c|c|c|c|}
\hline \multirow[b]{2}{*}{ Measures } & \multicolumn{2}{|c|}{ IFS total score } & \multicolumn{2}{|c|}{ FAB total score } \\
\hline & $r$ & Partial $r^{a}$ & $r$ & Partial $r^{a}$ \\
\hline IFS total score & - & - & $.92 * *$ & $.83 * *$ \\
\hline FAB total score & $.92 * *$ & $.83 * *$ & - & - \\
\hline Clock Drawing Test & $.75 * *$ & $.51^{*}$ & $.80 * *$ & $.62 * *$ \\
\hline Stroop Test (interference index) & .16 & -.14 & .09 & -.21 \\
\hline \multicolumn{5}{|l|}{ Zoo Map Test } \\
\hline \multicolumn{5}{|l|}{ Condition 1} \\
\hline Raw score & .19 & .28 & .23 & $.31 *$ \\
\hline Planning time & .25 & .03 & .19 & .06 \\
\hline Execution time & .06 & -.04 & -.025 & -.16 \\
\hline \multicolumn{5}{|l|}{ Condition 2} \\
\hline Raw score & $.43 * *$ & $.31^{*}$ & $.39^{*}$ & .26 \\
\hline Planning time & .05 & -.06 & .05 & -.05 \\
\hline Execution time & $-.57 * *$ & -.30 & $-.64 * *$ & $-.44 *$ \\
\hline \multicolumn{5}{|l|}{ Rule Shift Card } \\
\hline Errors Condition 1 & $-.39 *$ & -.21 & $-.35^{*}$ & -.18 \\
\hline Errors Condition 2 & $-.63 * *$ & $-.35^{*}$ & $-.65^{* *}$ & $-.43^{*}$ \\
\hline MMSE & $.73 * *$ & $.72 * *$ & $.69 * *$ & $.67 *$ \\
\hline Geriatric Depression Scale & -.17 & -.02 & -.16 & -.05 \\
\hline
\end{tabular}

Note: ${ }^{* *} p<.001 ; * p<.05 .{ }^{\text {a }}$ Controlled for sociodemographic variables (age and education) and MMSE, in the case of correlations with other measures of EF.

\section{Figure Captions}


Figure 1. Scores of patients with Alzheimer's disease (AD) and matched healthy controls on each of the IFS and FAB sub-tests

Figure 2. Receiver Operating Characteristic (ROC) curves of the IFS and the FAB in comparing Alzheimer's disease patients versus healthy controls 
Figure 1.

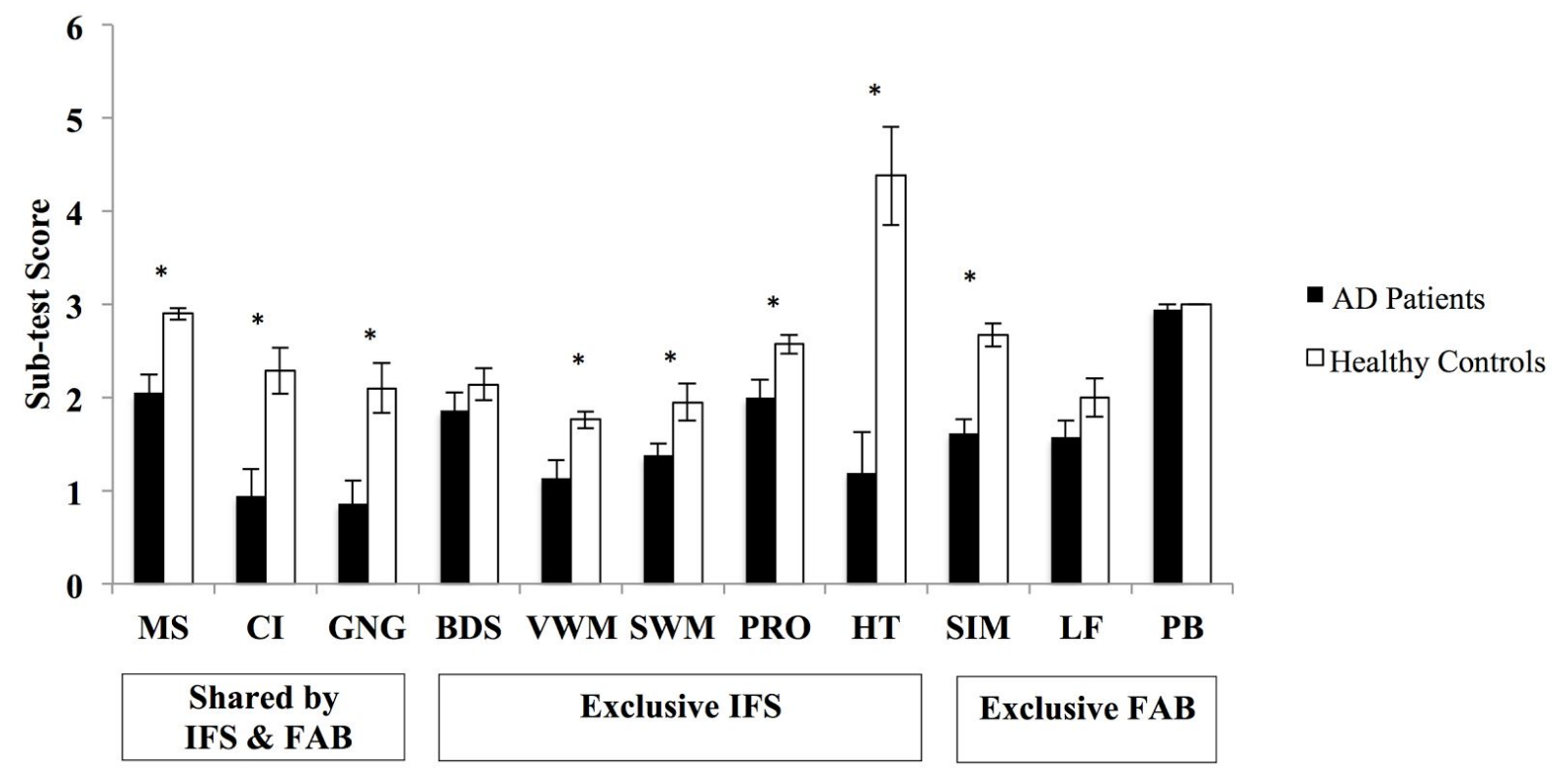

Note: $* p<.05 . \mathrm{MS}=$ motor series. $\mathrm{CI}=$ conflicting instructions. $\mathrm{GNG}=\mathrm{Go} /$ no go. $\mathrm{BDS}=$ backward digit span. VWM $=$ verbal working memory. $\mathrm{SWM}=$ spatial working memory. $\mathrm{PRO}=$ proverbs. $\mathrm{HT}=$ Hayling test. $\mathrm{SIM}=$ similarities. $\mathrm{LF}=$ lexical fluency. $\mathrm{PB}=$ prehension behavior 
Figure 2.

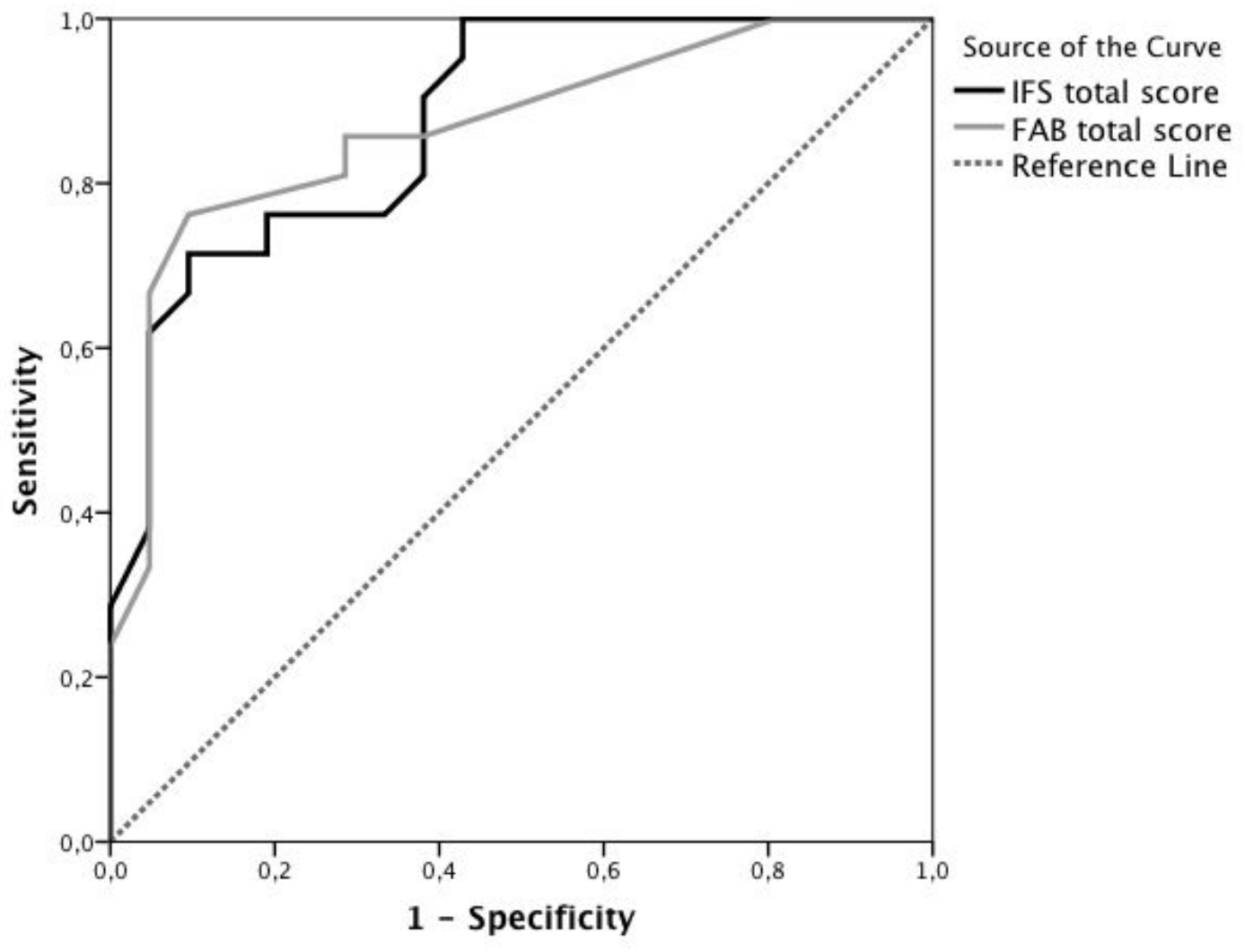

